\title{
IDENTIFICAÇÃO DE OPORTUNIDADES DE MELHORIA EM UM CURSO DE ADMINISTRAÇÃO POR MEIO DE MÉTODOS QUALITATIVOS DE PROCESSAMENTO DA INFORMAÇÃO ${ }^{1}$
}

\author{
Silvana Anita Walter ${ }^{2}$ \\ Gérson Tontini ${ }^{3}$ \\ Edmilson de Oliveira Lima ${ }^{4}$
}

\begin{abstract}
RESUMO: Este artigo tem como objetivo apresentar a abordagem metodológica de uma recente pesquisa que utiliza os métodos qualitativos de grupos de foco e diagrama de afinidades para identificar oportunidades de melhoria em cursos de administração. Na referida pesquisa, foram entrevistados seis grupos de foco de uma Instituição de Ensino Superior (IES) localizada em Curitiba, PR. Por meio de um método de hierarquização dos problemas citados pelos diferentes grupos, o estudo permitiu transformar conhecimento difuso e não estruturado em conhecimento estruturado, identificando e priorizando os 15 principais problemas do Curso de Administração da IES pesquisada. Este trabalho demonstra que os grupos de foco são uma alternativa para a identificação de oportunidades de melhoria, sem a necessidade de os problemas serem categorizados previamente. Como principais conclusões tem-se que o curso deve promover a integração de conteúdos das disciplinas e trabalhar a relação professor-aluno, procurando estabelecer uma relação de parceria no processo de ensino-aprendizagem. No que diz respeito à infra-estrutura, a IES deve resolver inicialmente aspectos de acesso (horário de atendimento, acesso, etc.). Os procedimentos metodológicos utilizados podem inspirar outras iniciativas de modo a ampliar suas contribuições no contexto das IES brasileiras.
\end{abstract}

Palavras-chaves: Pesquisa Qualitativa. Grupos de Foco. Gestão Universitária.

\section{INTRODUÇÃo}

O ambiente educacional passa por mudanças, tornando-se cada vez mais competitivo. Nesse cenário, a eficácia das estratégias de gestão de Instituições de Ensino Superior (IES) torna-se fundamental na competição para manter e conquistar alunos.

As IES buscam uma imagem positiva na sociedade e seus dirigentes querem

\footnotetext{
${ }^{1}$ Artigo apresentado no X Colóquio Internacional sobre o Poder Local, Salvador, BA, Dezembro/2006.

${ }^{2}$ Qualific Assessoria e Treinamento. Marechal Candido Rondon, PR. Mestre em Administração pela Universidade Regional de Blumenau. E-Mail: silvanaanita@gmail.com

${ }^{3}$ Programa de Pós Graduação em Administração da Universidade Regional de Blumenau-FURB. E-Mail: tontini@furb.br ${ }^{4}$ Programa de Pós Graduação em Administração, Centro Universitário Nove de Julho, São Paulo.. E-Mail: edmilsonolima@gmail.com
} 
assegurar o sucesso no ambiente do ensino superior. Para alcançar esse sucesso é necessário melhorar continuamente os padrões de qualidade e os processos educacionais, reduzindo, dessa forma, possíveis barreiras à aprendizagem (ALVES, 2003). Para tanto, a atenção à satisfação dos alunos é essencial, visto que este elemento pode, de acordo com seu estado, significar uma barreira ou um facilitador à aprendizagem.

Alves (2003) e Marzo-Navarro, Pedraja-Iglesias e Rivera-Torres (2005) ressaltam a importância da satisfação, apontando-a como um item de grande impacto na lealdade dos alunos. Nesse contexto, a avaliação da satisfação torna-se fundamental para 0 sucesso do relacionamento das IES com seus alunos em curto e em longo prazo.

A maioria das IES e cursos de administração utilizam apenas procedimentos quantitativos para avaliar a satisfação de seus alunos ou o desempenho de seus cursos (WALTER; DREHER, 2005). Algumas avaliações realizadas pelas IES com métodos quantitativos enfocam a importância ou relevância de diferentes atributos e dimensões de seus cursos que são relacionados com a qualidade, a satisfação e a lealdade dos alunos. Esse é o caso das avaliações relatadas por Alves (2003), DeShields Jr, Kara e Kaynak (2005), DeWitz e Walsh (2002), Hennig-Thurau, Langer e Hansen (2001), Karemera, Reuben e Sillah (2003), Marks (2000), Marzo-Navarro, Pedraja-Iglesias e RiveraTorres (2005) e Wilhelm (2004).

Em contrapartida, os estudos de Alves (2000), Alves e Raposo (1999), Walter, Tontini e Domingues (2005) utilizaram métodos quantitativos para investigar não apenas os influenciadores da qualidade, da satisfação e da lealdade dos alunos de IES, mas também para estudar as oportunidades de melhoria de seus cursos.

Já outros estudos combinaram métodos qualitativos com métodos quantitativos. Gonçalves Filho, Guerra e Moura (2003) utilizaram a abordagem qualitativa de grupos de foco e de consulta a especialistas da própria universidade estudada para identificar influenciadores da qualidade, da satisfação e da lealdade, utilizando-os, em seguida, num questionário quantitativo para mensurar sua importância. Gonçalves (2003) também realizou uma etapa qualitativa, por meio de questões abertas para levantamento dos influenciadores da satisfação que, em seguida, foram utilizados na avaliação quantitativa da qualidade de serviços e da satisfação dos alunos.

Há de se observar que nenhum dos estudos identificados utilizou métodos qualitativos para identificação de oportunidades de melhoria nas IES por meio da consideração dos influenciadores da qualidade, da satisfação e da lealdade dos alunos.

No Brasil, a utilização de métodos qualitativos, particularmente dos grupos de foco, como método de coleta de dados para auxiliar, de forma sistematizada, a gestão das diferentes organizações, ainda é algo raro. Os métodos qualitativos são muito raros, por exemplo, na avaliação da satisfação de alunos para melhorar o desempenho das IES. Por meio de uma abordagem que prioriza a contextualização, as pesquisas qualitativas, além de revelarem os problemas existentes nas IES e nos cursos, podem apontar detalhes da estrutura desses problemas, permitindo ações de resolução mais específicas e eficazes.

Os gestores de cursos de administração (cursos que interessam particularmente a este estudo) necessitam de métodos estruturados para avaliar qualitativamente seus cursos, suas carências, as sugestões e os problemas relacionados às IES, que são percebidos pelos alunos. Na prática, os coordenadores dos cursos ouvem os alunos, as turmas, os representantes de diretórios acadêmicos ou os professores sem utilizarem um método preparado adequadamente. Tal modo de coleta de dados geralmente se mostra insuficientemente organizado e fundamentado, não levando, por isso, os gestores a terem confiança nesses resultados para tomada de decisões. 
Neste contexto, tem-se o intuito de propor a utilização de métodos de pesquisa qualitativa, por meio de entrevistas com grupos de focos e do diagrama de afinidades, para identificar e priorizar oportunidades de melhoria e direcionar ações de gestão em cursos de administração.

Este artigo, em seu primeiro momento, tem como objetivo apresentar a abordagem metodológica de uma recente pesquisa que utiliza os métodos qualitativos de grupos de foco e diagrama de afinidades para identificar oportunidades de melhoria em cursos de administração que poderão auxiliar o direcionamento de ações de gestão universitária. Em um segundo momento, tem o propósito de apresentar os resultados e as discussões, bem como propor a utilização da pesquisa qualitativa, por meio de entrevistas com grupos de foco, para identificar oportunidades de melhoria e direcionar ações de gestão em cursos de administração. Para atingir os objetivos propostos, na seção 2, descrevem-se os procedimentos metodológicos para a condução de entrevistas com grupos de foco; na seção 3, como foram realizadas as entrevistas com os grupos de foco. A seção 4 apresenta os procedimentos de análise dos dados. A seção 5 , os resultados e as discussões do estudo e a seção 6 traz as considerações finais deste estudo.

\section{PROCEDIMENTOS PARA A CONDUÇÃO DE ENTREVISTAS COM GRUPOS DE FOCO}

A realização de entrevistas com grupos de foco consiste em reunir de seis a doze participantes, liderados por um ou dois moderadores, que passam um período discutindo profundamente determinado tópico ou conceito. O objetivo é compreender o que as pessoas têm a dizer sobre o tema abordado e o porquê, estimulando-as a detalhar aquilo que dizem (HAIR JÚNIOR et al., 2005; BERRY, 1996; MATTAR, 1996; FLICK, 2004; RUEDIGER e RICCIO, 2004; REA; PARKER, 2000). No entanto, Albrecht (1992) ressalta que a eficiência do moderador, também chamado de entrevistador, pode ser melhor com grupos menores, formados geralmente por cinco a dez pessoas.

Mattar (1996, p. 64) define as entrevistas com grupos de foco como um método pouco estruturado, "conduzido por um moderador experiente, simultaneamente, com um pequeno número de participantes para obter dados sobre determinado assunto focalizado". Se, para Mattar, a técnica prevê a participação de um moderador experiente, para Albrecht (1995, p. 113), "qualquer pessoa razoavelmente capaz pode [...]" usá-la. No entanto, ambos os autores concordam que o papel do moderador é fundamental, pois cabe a ele interpretar os dados fornecidos pelos participantes e conduzir a entrevista com os mesmos.

Ao moderador cabe, ainda, incentivar a participação de todos, deixando-os à vontade e convidando-os a falar, evitando, assim, que apenas alguns participantes dominem a entrevista. O incentivo pode começar pela explicação do motivo da reunião e da importância da participação de todos. Além disso, Mattar (1996, p. 65) afirma que "sua principal função é focalizar a atenção dos participantes para determinada experiência, e a partir dela obter os dados desejados" (sic). Recomenda-se formar um grupo com pessoas que possuam o mesmo perfil ou, como esclarece Mattar (1996, p. 64), "pessoas com características demográficas, socioeconômicas e de estilo de vida extremamente homogêneos", para que se possa manter o foco e não ocorram posições muito conflitantes causadas pelas diferentes realidades dos participantes. Considerando-se este critério, recomenda-se evitar selecionar para essas entrevistas participantes de diferentes cursos ou ênfases ou mesclar turmas iniciais e finais. 
Em relação ao tempo de duração dessas entrevistas, Mattar (1996) aconselha que seja de, no mínimo, uma hora e trinta minutos e, no máximo, de três horas, para permitir que a questão em estudo seja completamente discutida. Quanto ao tempo de aquecimento do grupo para se chegar ao início do tratamento das questões centrais, o autor o estima em 30 minutos.

Para Albrecht (1992) a abordagem metodológica dos grupos de foco não busca, necessariamente, validade estatística. Para o autor, busca descobrir os principais fatores que influenciam os elementos pesquisados junto aos participantes do grupo de foco. No caso da pesquisa apresentada neste artigo, procurou-se identificar os principais problemas, sob o ponto de vista dos alunos, do Curso de Administração da IES estudada, e não a validade estatística, conforme explica Albrecht (1992).

Nos grupos de foco, o entrevistador ou moderador segue uma lista predeterminada de tópicos de discussão, mas adaptável segundo as dinâmicas do momento da entrevista. Entretanto, deve permitir que os participantes respondam com suas próprias palavras, bem como deve aprofundar as respostas superficiais por meio de questões de sondagem. Albrecht (1995, p. 113) alerta o moderador de que "o segredo está em compreender as descobertas, interpretar o que os participantes do grupo Ihe disseram e relacionar isso" com o objetivo da pesquisa. Isso significa que se faz necessário o trabalho de um moderador devidamente preparado, treinado e experiente, até porque cabe, geralmente, a ele preparar o relatório de pesquisa.

Mattar (1996, p. 67) cita algumas limitações das entrevistas com grupos de foco em virtude da subjetividade da interpretação, da dependência da experiência e da percepção do moderador. Assim, o autor sugere que, "em função dessas fraquezas, a entrevista focalizada em grupos é uma técnica muito recomendável para pesquisas exploratórias e não para pesquisas conclusivas". Contudo, no estudo que se fez, tais limitações foram minimizadas com a elaboração de um roteiro de discussões, a realização de um préteste e a utilização dos procedimentos de análise.

\section{DESCRIÇÃO DA REALIZAÇÃO DAS ENTREVISTAS COM OS GRUPOS DE FOCO}

Neste estudo, identificaram-se e coletaram-se os dados por meio de entrevistas de grupos de foco. Participaram dessas entrevistas alunos voluntários de fases intermediárias de um curso de administração de uma universidade privada de Curitiba, PR, perfazendo o total de seis grupos de foco, aos quais, na ocasião, se informou sobre a gravação das entrevistas e se solicitou autorização para utilizá-las e divulgar o conteúdo das mesmas.

Durante as entrevistas, realizadas em uma sala pré-reservada da IES enfocada, os alunos participantes dos grupos de foco - alguns destes compostos por oito, outros, por nove, e outros, ainda, por dez universitários - sentaram-se em círculo para participarem das discussões que foram gravadas e, posteriormente, transcritas ipsis litteris para análise.

A condução das entrevistas com os grupos de foco foi precedida pela elaboração de um guia de discussões que serviu como roteiro para a ocasião. O guia de discussões contemplou três etapas, assim identificadas:

1) introdução dos participantes ao tema, com relato dos objetivos e das regras de discussão;

2) início das discussões por meio do roteiro composto por questões semi-estruturadas;

3) resumo das informações mais significativas da discussão. 
Visando à eficácia do "guia de discussões" e a preparação dos moderadores, aplicouse um pré-teste a um grupo de foco experimental, composto por universitários da $9^{a}$ fase de um curso administração de outra IES, da cidade de Blumenau, SC. Essa fase foi escolhida para aplicação do pré-teste devido à experiência dos entrevistados com seu curso.

Para Hair Júnior et al. (2005, p. 230), "nenhum questionário deve ser administrado antes que o pesquisador avalie a provável exatidão e coerência das respostas". O mesmo autor indica que tal avaliação pode ser feita por meio de pré-testes dos instrumentos de pesquisa aplicados a uma pequena amostra semelhante à população estudada. O préteste, para Lakatos e Marconi (1996, p. 227), tem como uma das principais funções testar o instrumento de coleta de dados quanto às "[...] reações do entrevistado, sua dificuldade de entendimento, tendência para esquivar-se de questões polêmicas ou 'delicadas', seu embaraço com questões pessoais, etc.". Ainda, para esses autores, o pré-teste evidencia se há ambigüidade entre as questões, perguntas supérfluas, adequação da ordem das questões, se são em número excessivo ou se necessitam de complemento.

O pré-teste também pode evidenciar três elementos essenciais que devem estar presentes em questionários ou entrevistas: fidedignidade, validade e operatividade (LAKATOS; MARCONI, 1996).

No que se refere ao pré-teste aplicado desta pesquisa, analisaram-se todas as etapas do guia de discussões até considerá-lo válido. O guia de discussões ficou estruturado com as seguintes questões:

a) Quais suas expectativas em relação ao curso de administração? Comentem o que vocês esperavam do curso de administração ao ingressar nesta IES;

b) Das expectativas que vocês tinham em relação ao curso, quais foram atendidas e quais não foram atendidas até o momento?

c) Na visão de vocês, o que falta para o curso?

d) Se vocês fossem coordenadores de curso, o que vocês fariam para melhorar o curso de administração e a universidade?

e) Se vocês fossem coordenadores do curso, quais seriam suas prioridades para assegurar a qualidade deste curso?

f) Como vocês avaliam a infra-estrutura da universidade e do curso? Quais as suas prioridades de melhoria na infra-estrutura da universidade e do curso?

g) Quais os pontos fortes que se destacam neste curso de administração?

h) Quais são os pontos fracos que se destacam neste curso de administração?

i) Lembrem-se de uma situação ou acontecimento do curso que thes tiouxe satisfação;

j) Lembrem-se de uma situação ou acontecimento do curso que Ihes to puxe insatisfação.

Após a aplicação do pré-teste, realizaram-se as entrevistas com os seis grupps de foco na IES estudada e se conduziram as discussões até se atingir a saturação tf órica da pesquisa. Para Lima (2005, p. 6), o que determina o fim da coleta de dados em pesquisa qualitativa é a saturação teórica, que ocorre quando as entrevista\$ não acrescentam novos dados ou informações relevantes à pesquisa. De acordo com Claser e Strauss (1967 apud GODOY, 2000), a saturação teórica ocorre quando nen uuma 
categoria nova ou relevante está emergindo dos dados. Apesar da denominação "saturação teórica" ser mais freqüentemente associada à literatura de teoria embasada (grounded theory), considerou-se, nessa pesquisa, que houve a saturação teórica a partir do momento em que os grupos de foco não acrescentaram mais problemas ou fatos novos relevantes para serem considerados na pesquisa.

\section{PROCEDIMENTOS DE ANÁLISE DOS DADOS}

A análise dos dados obtidos por meio dos grupos de foco foi realizada com a aplicação do método do diagrama de afinidades (MIZUNO, 1993), também conhecido como Método KJ (KAWAKITA, 1991) ou "Language Processing Method" (SHIBA, 1994). Este método foi escolhido por sua praticidade e possibilidade de auxílio na organização de dados desordenados, sendo conveniente a novas maneiras de pensar, possibilitando a visualização das análises de forma não tradicional ou pré-concebida. Segundo Lee e Neewcomb (1996, p. 16) esta técnica é "projetada para organizar uma grande quantidade de informações complexas e qualitativas (dados lingüísticos) e para clarificar os itens envolvidos". Ainda segundo Kato e Kunifuji (1997), o método KJ é útil para reconhecer os pontos comuns do problema e atingir o consenso, suportando ao mesmo tempo pensamentos divergentes e convergentes.

No método do diagrama de afinidades, as declarações são sintetizadas e fundidas por afinidade semântica e intuitiva em uma hierarquia com crescente grau de generalização. Segundo Mizuno (1993), as declarações e idéias dos participantes são escritas em cartões e estes agrupados por afinidade semântica, sem uma classificação prévia racional. Assim, as categorias que emergem das declarações não seguem uma lógica préconcebida, podendo revelar a estrutura dos problemas. A figura 1 mostra um exemplo de diagnóstico usando o diagrama de afinidades em que são mostradas as declarações, que formam as categorias, que por sua vez, resultam em uma dimensão.

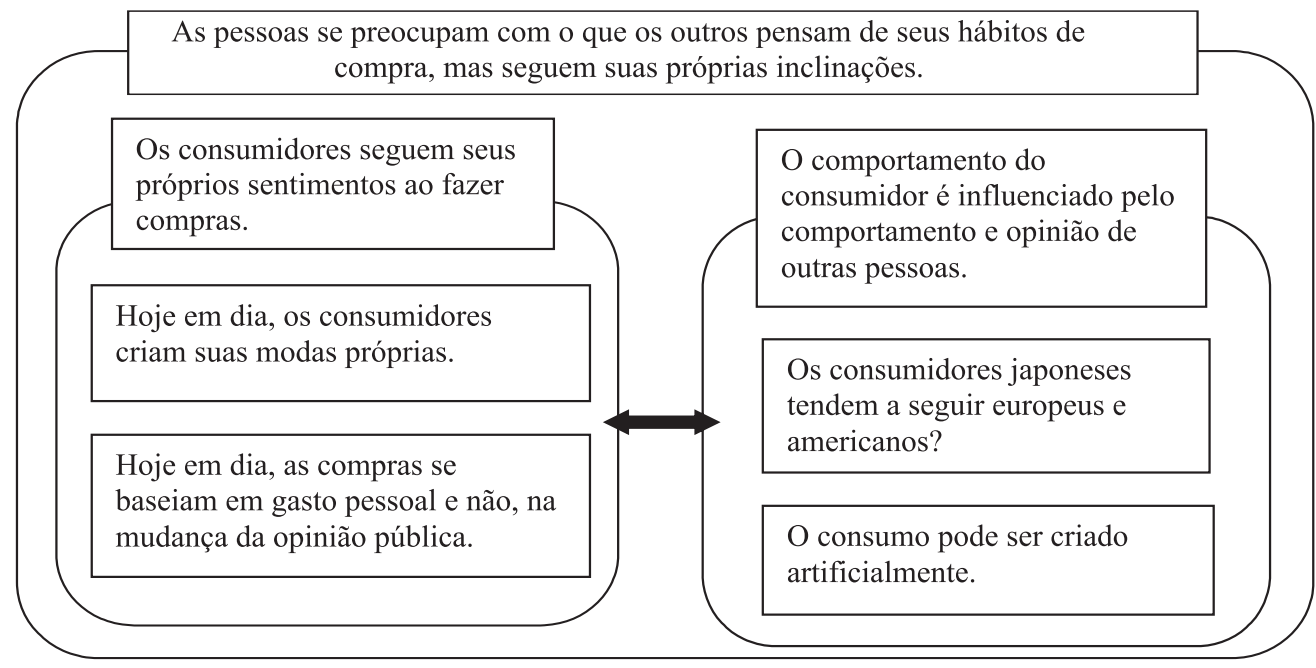

Figura 1: Exemplo de um segmento de um diagrama de afinidades Fonte: Adaptado de Mizuno, 1993. 
As relações e análises das transcrições dos grupos de foco dessa pesquisa foram desenvolvidas com auxílio do editor de texto word e planilha eletrônica excel, criando-se categorias de atributos por agrupamentos semânticos, as quais foram reunidas em categorias maiores, denominadas de dimensões. Além das análises das relações por agrupamentos semânticos, as declarações foram priorizadas de acordo com o número de vezes que os mesmos problemas foram citados pelos diferentes grupos de foco, conforme será descrito na próxima seção.

\section{RESULTADOS E DISCUSSÕES}

Processaram-se os resultados da aplicação dos grupos de foco procurando-se identificar os problemas atuais do curso de administração estudado. Reuniram-se os problemas, também denominados de aspectos ou declarações, identificados por meio das entrevistas com os grupos de foco por afinidade, o que resultou nas seguintes dimensões:

1) curso com cultura conservadora;

2) curso com perfil teórico;

3) problemas de planejamento e integração dos planos de ensino e dos professores;

4) falhas de organização da coordenação do curso;

5) problemas de acesso à infra-estrutura;

6) outros problemas.

\subsection{CURSO COM CULTURA CONSERVADORA}

O perfil conservador da cultura do curso emergiu de aspectos relacionados à postura dos professores e pouca comunicação sobre as ações do curso aos alunos (Figura 2).

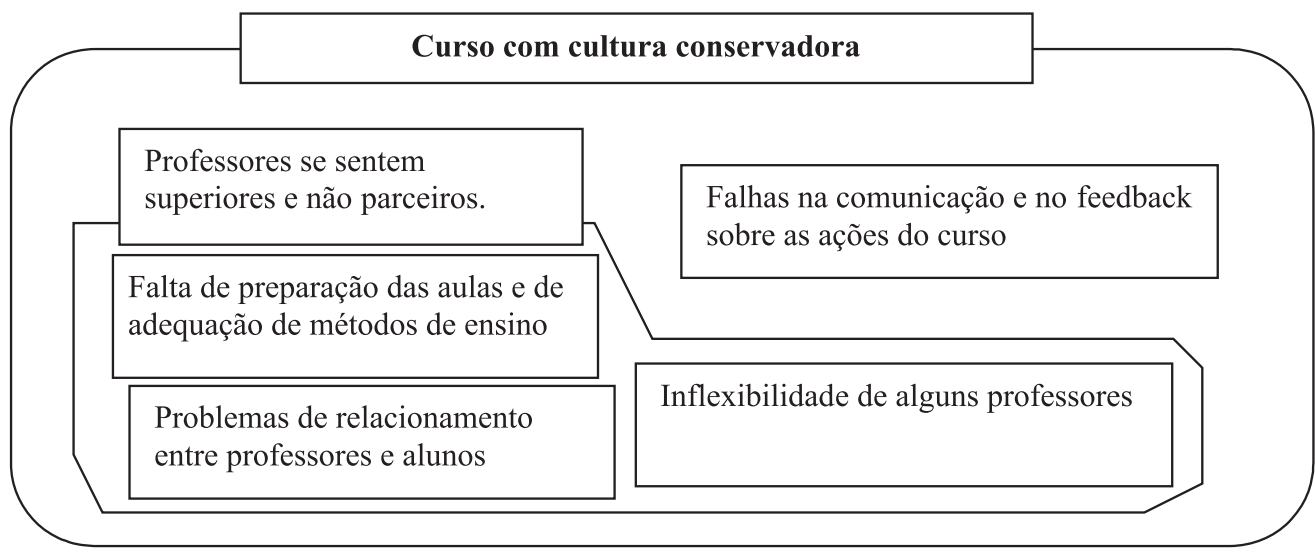

Figura 2: Dimensão curso com cultura conservadora

Fonte: dados da pesquisa. 
Em referência às categorias apresentadas na Figura 2, os aspectos apresentados pelos grupos de focos nas categorias $a, b$ e $d$ originaram a subdimensão professores se sentem superiores e não parceiros, que por sua vez, em conjunto com a categoria c, formaram a dimensão curso com cultura conservadora. O detalhamento desta dimensão pode ser observado a seguir:

a) falta de preparação das aulas e de adequação de métodos de ensino: a falta de adequação ou de diversidade de métodos de ensino foi o item mais citado pelos grupos de foco nesta categoria; outros itens foram a falta de disposição dos professores para preparar e conduzir as aulas, a falta de cursos didáticos para os professores e a utilização de linguagem técnica que não prende a atenção do aluno;

b) problemas de relacionamento entre professores e alunos: nesta categoria, os grupos de foco apontaram dificuldades de relacionamento com os professores, como a falta de imparcialidade no acompanhamento pedagógico, a falta de recepção adequada aos calouros, as comparações entre alunos feitas pelos professores, a falta de ética de alguns professores, a falta de comprometimento dos professores com a qualidade da formação dos alunos e a falta de humildade de alguns professores em sala de aula. Este último item foi o mais citado pelos grupos de foco nesta categoria;

c) falhas na comunicação e no feedback sobre as ações do curso: agruparam-se, nesta categoria, possíveis falhas de comunicação do curso de administração estudado indicadas pelos grupos de foco, como a falta de acesso e diálogo com a coordenação, algumas informações que não chegam até os alunos, falta de retorno das pesquisas de satisfação e avaliação institucional para os alunos e o método de aplicação desta avaliação;

d) inflexibilidade de alguns professores: nesta categoria, emergiram dúvidas em relação aos critérios de avaliação e o fato de, algumas vezes, os professores não trocarem os horários das aulas para viabilizar atividades, como, por exemplo, visitas a empresas com os alunos.

\subsection{CURSO COM PERFIL TEÓRICO}

Os principais aspectos revelados com o surgimento desta dimensão estão expostos na Figura 3.

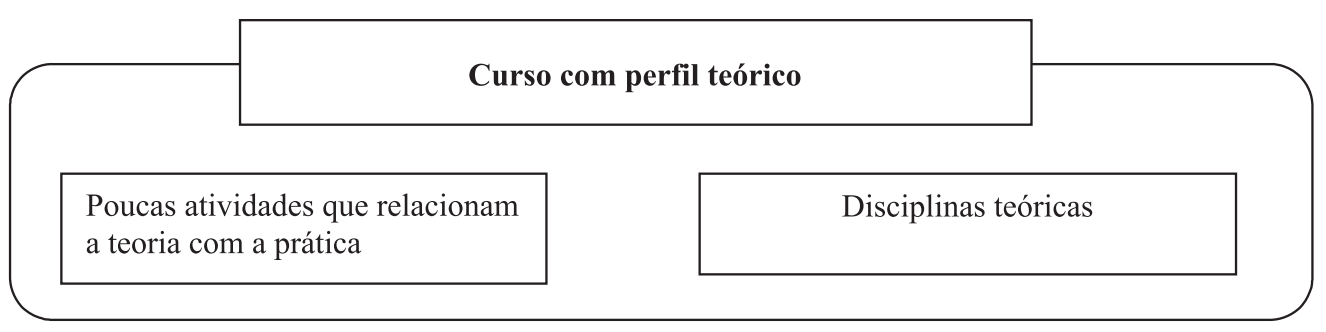

Figura 3: Dimensão curso com perfil teórico

Fonte: dados da pesquisa. 
O detalhamento da dimensão apresentada na Figura 3 pode ser observado nas seguintes categorias e aspectos:

a) poucas atividades que relacionam a teoria com a prática: emergiram, para esta categoria, a falta de empresa júnior, a falta de mais parcerias para a realização de atividades práticas e estágios, a falta de relevância das atividades praticadas nos estágios para o aprendizado dos alunos e a falta de programas de extensão, visitas e viagens para os alunos, sendo estes dois últimos os mais citados;

b) disciplinas teóricas: nesta categoria, os grupos de foco destacaram os itens excesso de teoria e falta de aulas práticas nas disciplinas, falta de exemplos práticos nas aulas, falta de experiência prática dos professores e visitas a empresas sem relação direta com o conteúdo estudado nas disciplinas. O problema mais citado pelos alunos foi falta de aulas práticas.

\subsection{PLANEJAMENTO E INTEGRAÇÃO DOS PLANOS DE ENSINO E DOS PROFESSORES}

A partir das entrevistas com os grupos de foco, as principais categorias que emergiram ligadas ao planejamento e à integração dos planos de ensino e dos professores podem ser visualizados na Figura 4.

Planejamento e integração dos planos de ensino e dos professores

Planejamento das

atividades do curso
Integração entre as

disciplinas e os professores
Disciplinas que não estão

voltadas à realidade e à

necessidade dos alunos

\section{Figura 4: Dimensão planejamento e integração dos planos de ensino e dos} professores

Fonte: dados da pesquisa.

O detalhamento da dimensão apresentada na Figura 4 pode ser observado nas seguintes categorias e aspectos:

a) planejamento das atividades do curso: os grupos de foco indicaram alguns problemas que podem estar relacionados ao planejamento das atividades do curso, como os períodos de sobrecarga de trabalhos e avaliações, a falta de planejamento com atividades que necessitam de livros da biblioteca e o excesso de palestras. O primeiro destes três itens foi o mais citado;

b) integração entre as disciplinas e os professores: falta de orientação e embasamento para alguns trabalhos dos alunos, disciplinas que não estão vinculadas umas às outras, disciplinas que precisam ser mudadas de período, falta de integração entre os professores em relação aos conteúdos das disciplinas e a falta de instruções prévias sobre o trabalho de conclusão de curso (TCC) foram os itens identificados nesta categoria. Destes, o mais citado foi a falta de integração entre os professores para harmonizar aos conteúdos das disciplinas; 
c) disciplinas que não estão voltadas à realidade e à necessidade dos alunos: foram citados, nesta categoria, os itens baixa qualidade das palestras oferecidas, o foco dos trabalhos que é voltado a grandes empresas ou empresas internacionais (o que, para a maioria dos alunos, segundo os grupos de foco, não condiz com a realidade de seu cotidiano), a incompatibilidade de algumas disciplinas com o curso, a não- existência de aulas de informática, a falta de temas atuais na grade curricular (meio ambiente, responsabilidade social, etc.), a não-existência de disciplinas optativas, a falta de atualização de alguns professores e de parte dos conteúdos das disciplinas.

\subsection{FALHAS DE ORGANIZAÇÃO DA COORDENAÇÃO DO CURSO}

Os aspectos que emergiram para esta dimensão constam da Figura 5.

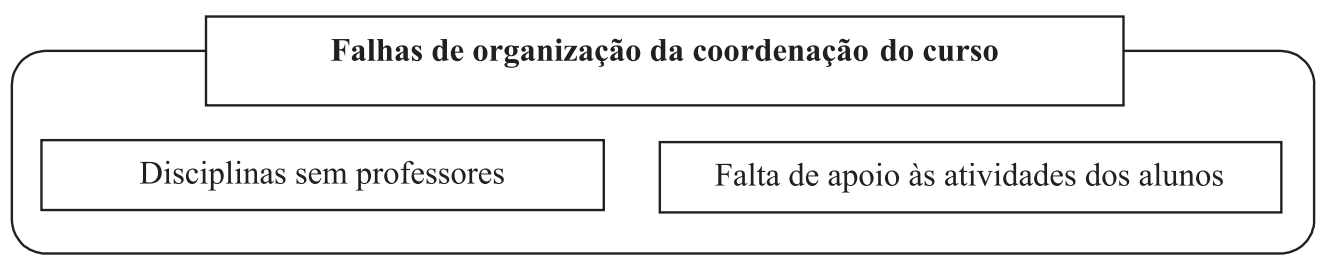

Figura 5: Dimensão falhas de organização da coordenação do curso

Fonte: dados da pesquisa.

No que tange à dimensão falhas de organização da coordenação do curso, os aspectos que emergiram dos grupos de foco foram:

a) disciplinas sem professores: nesta dimensão, os grupos de foco citaram possíveis falhas de organização da coordenação, como a falta de professores e, o mais citado, critérios de contratação e seleção dos professores. Contudo, este último fator pode estar relacionado à insatisfação dos alunos com o desempenho de alguns professores em sala de aula, mais especificamente em relação aos métodos de ensino;

b) falta de apoio às atividades dos alunos: foi apontada, nesta dimensão, a falta de apoio às atividades promovidas pelos alunos do curso, como, por exemplo, organização das semanas acadêmicas e de palestras.

\subsection{PROBLEMAS DE INFRA-ESTRUTURA E DE ACESSO À INFRA-ESTRUTURA}

Os principais aspectos revelados com o surgimento desta dimensão estão na Figura 6 . 


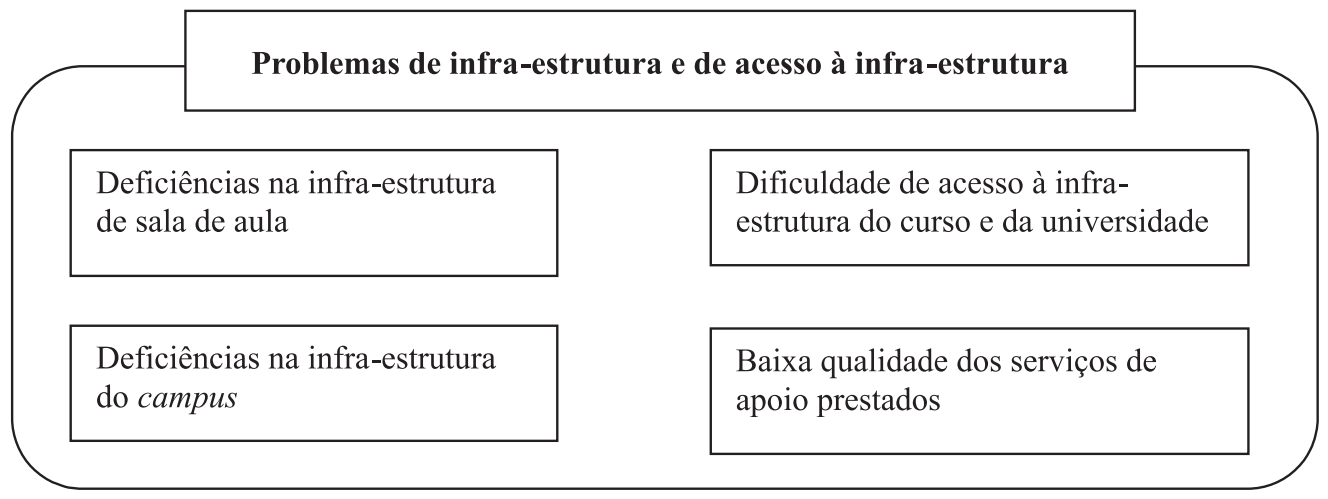

Figura 6: Dimensão problemas de acesso à infra-estrutura Fonte: dados da pesquisa.

Os aspectos de melhoria relatados pelos grupos de foco no que se refere à dimensão problemas de acesso à infra-estrutura foram assim detalhados:

a) deficiências na infra-estrutura de sala de aula: problemas de ventilação nas salas de aula e desejo por disponibilidade de recursos de informática (por exemplo, projetor multimídia e computadores) em todas as salas de aula do campus, foram os itens citados nesta categoria;

b) deficiências na infra-estrutura do campus: quanto a esta categoria, foram citadas deficiências relativas aos serviços de apoio como laboratórios de informática, biblioteca, estacionamento, auditório, serviços de fotocópia e impressão, sendo os problemas mais relevantes da infra-estrutura do campus a falta de modernidade dos laboratórios de informática e de computadores, além da falta ou desatualização de títulos e exemplares de obras da biblioteca;

c) dificuldade de acesso à infra-estrutura do curso e da universidade: emergiram para esta categoria os problemas de acesso aos recursos disponíveis, como multimídia, laboratórios de informática, biblioteca e quadra de esportes para os alunos da instituição. O item de insatisfação mais citado pelos grupos de foco, nesta categoria, foi os horários de acesso aos laboratórios de informática;

d) baixa qualidade dos serviços de apoio prestados: dos itens identificados nesta categoria, o mais citado foi o atendimento dos funcionários da secretaria e os demais foram a qualidade da cantina e a limpeza e manutenção dos banheiros.

\subsection{OUTROS PROBLEMAS}

As entrevistas com grupos de foco também apontaram outros problemas de caráter geral que não estão mencionados nas categorias anteriormente citadas: baixa qualidade de ensino e baixa aprendizagem percebida. $\mathrm{Na}$ análise de afinidades, estes dados são chamados de isolados e, segundo Mizuno (1993), seus agrupamentos ou relações não devem ser forçados. 


\subsection{ANÁLISE DOS PROBLEMAS PRIORITÁRIOS E DECISÕES DE MELHORIA}

Na Figura 7, mostra-se um quadro geral das dimensões surgidas da análise dos problemas identificados com os grupos de foco. Nela, são relacionadas as prioridades de cada item de acordo com o número de vezes com que os mesmos problemas foram citados nos grupos de foco.

\begin{tabular}{|c|c|c|c|c|c|}
\hline Dimensões e problemas identificados & Citações & \begin{tabular}{|c|} 
Peso da \\
Categoria \\
(PC)
\end{tabular} & $\begin{array}{c}\text { Peso } \\
\text { Relativo } \\
\text { da (PE) }\end{array}$ & $\begin{array}{c}\text { Peso } \\
\text { Geral } \\
\text { (PCxPE) }\end{array}$ & $\begin{array}{c}\text { Priori- } \\
\text { dade }\end{array}$ \\
\hline CURSO COM CULTURA CONSERVADORA & 51 & & & & \\
\hline $\begin{array}{l}\text { Falta de preparação das aulas e adequação de métodos } \\
\text { de ensino }\end{array}$ & 13 & \multirow{4}{*}{0,33} & 0,26 & 0,08 & 2 \\
\hline $\begin{array}{l}\text { Problemas de relacionamento entre professores e } \\
\text { alunos }\end{array}$ & 13 & & 0,26 & 0,08 & 2 \\
\hline $\begin{array}{l}\text { Falhas na comunicação e no feedback das ações do } \\
\text { curso }\end{array}$ & 12 & & 0,22 & 0,07 & 4 \\
\hline Inflexibilidade de alguns professores & 13 & & 0,26 & 0,08 & 2 \\
\hline CURSO COM PERFIL TEÓRICO & 20 & & & & \\
\hline Poucas atividades que relacionam a teoria e a prática & 10 & \multirow{2}{*}{0,13} & 0,5 & 0,065 & 6 \\
\hline Disciplinas teóricas & 10 & & 0,5 & 0,065 & 6 \\
\hline $\begin{array}{l}\text { PLANEJAMENTO E INTEGRAÇÃO DOS } \\
\text { PLANOS DE ENSINO E DOS PROFESSORES }\end{array}$ & 30 & & & & \\
\hline Planejamento das atividades do curso & 05 & \multirow{3}{*}{0,19} & 0,16 & 0,03 & 10 \\
\hline Integração entre as disciplinas e os professores & 09 & & 0,30 & 0,06 & 8 \\
\hline $\begin{array}{l}\text { Disciplinas que não estão volta das à realidade e às } \\
\text { necessidades dos alunos }\end{array}$ & 16 & & 0,54 & 0,10 & 1 \\
\hline $\begin{array}{l}\text { FALHAS DE ORGANIZAÇÃO DA } \\
\text { COORDENAÇÃO DO CURSO }\end{array}$ & 20 & & & & \\
\hline Disciplinas sem professores & 10 & \multirow{2}{*}{0,13} & 0,5 & 0,065 & 7 \\
\hline Falta de apoio às atividades dos alunos & 10 & & 0,5 & 0,065 & 7 \\
\hline $\begin{array}{l}\text { PROBLEMAS DE INFRA -ESTRUTURA E DE } \\
\text { ACESSO À INFRA-ESTRUTURA }\end{array}$ & 34 & & & & \\
\hline Deficiências na infra-estrutura de sala de aula & 02 & \multirow{4}{*}{0,22} & 0,06 & 0,01 & 11 \\
\hline Deficiências na infra-estrutura do campus & 12 & & 0,36 & 0,07 & 5 \\
\hline $\begin{array}{l}\text { Dificuldade de acesso à infra -estrutura do curso e da } \\
\text { universidade }\end{array}$ & 13 & & 0,38 & 0,08 & 3 \\
\hline $\begin{array}{l}\text { Baixa qualidade dos serviços de infra } \\
\text { prestados }\end{array}$ & 07 & & 0,21 & 0,04 & 9 \\
\hline & 155 & 1,00 & & 1,00 & \\
\hline
\end{tabular}

Figura 7: Análise das dimensões e fatores prioritários de melhoria Fonte: dados da pesquisa.

As dimensões prioritárias para melhoria, de acordo com a análise da repetição da categoria nos grupos de foco, são: curso com cultura conservadora, problemas de infraestrutura e de acesso à infra-estrutura, planejamento e integração dos planos de ensino e dos professores, seguidos de curso com perfil teórico e coordenação. Esta priorização foi conseguida dividindo-se o número de citações que emergiram em cada dimensão pelo total de citações.

Os fatores individuais identificados como prioritários para melhoria, a partir da Figura 7, são: 
1) foco do curso: disciplinas que não estão voltadas à realidade e necessidades dos alunos;

2) aspectos de atitude dos professores: falta de preparação das aulas, relacionamento entre professores e alunos, e inflexibilidade por parte de alguns professores;

3) dificuldade de acesso à infra-estrutura do curso e da universidade;

4) falhas na comunicação e feedback das ações do curso;

5) deficiências na infra-estrutura do campus;

6) poucas atividades que relacionam a teoria e a prática e disciplinas teóricas (perfil teórico do curso);

7) falhas de organização da coordenação e falta de apoio às atividades dos alunos;

8) integração entre as disciplinas e os professores;

9) baixa qualidade dos serviços de infra-estrutura prestados;

10) planejamento das atividades do curso;

11) deficiências na infra-estrutura de sala de aula.

Assim, as ações de melhoria a serem priorizadas são:

1) integração de conteúdos por meio de reuniões pedagógicas promovidas e trabalhar a relação professor-aluno, procurando estabelecer relação de parceria no processo de ensino-aprendizagem;

2) solucionar, primeiramente, aspectos de acesso à infra-estrutura (horário de atendimento, facilidade de acesso, etc.), devido ao fato de não necessitarem de investimentos.

\section{CONSIDERAÇÕES FINAIS}

Normalmente, as IES utilizam-se de instrumentos quantitativos para avaliar a qualidade de seus cursos e a satisfação de seus alunos com os serviços que oferecem. De forma geral, são aplicados questionários para que os alunos avaliem o desempenho dos professores em sala de aula, a organização dos cursos e a infra-estrutura. Apesar da grande polêmica existente sobre a validade ou não de se utilizar a percepção dos alunos para a avaliação dos cursos e professores, este método difundiu-se rapidamente entre as IES, particularmente entre aquelas de caráter privado. Os resultados dessas avaliações mostram pontos fracos e fortes dos cursos (segundo a perspectiva dos alunos) utilizandose uma lista de atributos previamente identificados. Porém, pouco se consegue saber sobre a estrutura dos problemas (suas causas e conseqüências) identificados junto aos alunos pelas avaliações. Assim, muitas dessas pesquisas quantitativas são utilizadas apenas para a apreciação de tendências, resultando em poucas ações efetivas de melhoria dos cursos avaliados.

Devido ao caráter generalista e à polêmica que cerca a avaliação quantitativa efetuada por alunos, as ações de melhoria, quando efetuadas, são baseadas mais em informações de caráter qualitativo e intuitivo, por meio de sondagens feitas pelos coordenadores de curso. Porém, essas pesquisas qualitativas têm sido efetuadas de forma pouco formal 
ou estruturadas, dificultando aos gestores saberem qual a relevância das informações obtidas.

Os grupos de foco e o método do diagrama de afinidades são uma alternativa para o tratamento das informações e a identificação de oportunidades de melhoria, sem a necessidade de os problemas serem categorizados previamente. Este trabalho demonstra que sua aplicação pode ser útil para sistematizar ações de melhoria para cursos de administração, permitindo, inclusive, inferir um certo grau de prioridade aos problemas encontrados.

Outra possibilidade de uso do método de grupos de foco e do diagrama de afinidades pode ser a utilização em reuniões de colegiado de curso para se obter uma visão mais abrangente dos problemas e não apenas a visão unilateral, a dos alunos.

Apesar de os problemas terem sido priorizados, os grupos de foco foram conduzidos para extrair pontos para melhoria, não podendo os resultados serem utilizados para se fazer uma avaliação global da qualidade do curso, principalmente em comparação com outras IES. Isto significa que o método não permite classificar um curso como de alta ou de baixa qualidade. Ele permite descobrir os problemas existentes nos cursos e não, sua gravidade.

Os métodos de pesquisa qualitativa, dentre eles o método de grupos de foco, podem ser utilizados de forma complementar aos métodos quantitativos na avaliação de cursos de administração ou de organizações de serviços em geral. A pesquisa qualitativa pode mostrar problemas estruturais e revelar dimensões e categorias importantes, enquanto as pesquisas quantitativas podem comprová-los e mensurá-los. Por outro lado, a pesquisa qualitativa pode ser utilizada após as pesquisas quantitativas para esclarecer as interrelações e as causas dos pontos fracos identificados na etapa quantitativa. Desta forma, o método qualitativo pode suprir (ou complementar) os pontos fracos da forma quantitativa de pesquisa.

\section{REFERÊNCIAS}

ALBRECHT, Karl. A única coisa que importa: trazendo o poder do cliente para dentro de sua empresa. 2. ed. São Paulo: Pioneira, 1995.

ALBRECHT, Karl. Serviços com qualidade: a vantagem competitiva. São Paulo: Makron Books, 1992.

ALVES, Helena Maria Baptista. As dimensões da qualidade no serviço educação: uma percepção dos alunos da universidade da Beira Interior. Revista Portuguesa de Gestão, v. 3, p. 78-89, out. 2000.

ALVES, Helena Maria Baptista. Uma abordagem de marketing à satisfação do aluno no ensino universitário público: índice, antecedentes e conseqüências. 2003. 285f. Tese (Doutorado em Gestão) - Universidade da Beira Interior, Covilhã, 2003.

ALVES, Helena Maria Baptista; RAPOSO, Mário. O Marketing nas universidades: um estudo exploratório sobre a satisfação dos alunos como clientes no ensino superior. Revista Portuguesa de Marketing, v. 3, n. 8, p. 67-80, 1999. 
BERRY, Leonard L. Serviços de qualidade máxima: guia prático de ação. Rio de Janeiro: Campus, 1996.

DESHIELDS JR, Oscar W; KARA, Ali; KAYNAK, Erdener. Determinants of business student satisfaction and retention in higher education: applying Herzberg's two-factor theory. International Journal of Educational Management, v. 19, n. 2, p. 128-139. 2005. Disponível em: <http://www.emeraldinsight.com/0951-354X.htm>. Acesso em: 10 dez. 2005.

DEWITZ, Joseph S; WALSH, Bruce Walsh. Self-Efficacy and College Student Satisfaction. Journal of Carrer Assessment, v. 10, n. 3, p. 315-326, ago. 2002. Disponível em: <http:/ /jca.sagepub.com/cgi/reprint/10/3/315>. Acesso em: $10 \mathrm{dez} .2005$.

FLICK, Uwe. Uma introdução à pesquisa qualitativa. 2. ed. Porto Alegre: Bookman, 2004.

GODOY, Arilda Schmidt. Avaliação da aprendizagem no ensino superior: um estudo exploratório a partir das opiniões dos alunos do primeiro e do último ano de três cursos de graduação. Administração On Line, v. 1, n. 1, jan./fev./mar. 2000. Disponível em: <http://www.fecap.br/adm_online/art11/arilda.htm>. Acesso em: 14 set. 2005.

GONÇALVES, Cristina Faria Fidelis. Qualidade do serviço da universidade pública: uma avaliação perceptiva. In: SIMPÓSIO DE ENGENHARIA DE PRODUÇÃO, 10., 2003; Bauru. Anais... Bauru, 2003, p. 1-4.

GONÇALVES FILHO, Cid; GUERRA, Renata Souza; MOURA, Alexandre. Mensuração de Satisfação, Qualidade, Lealdade, Valor e Expectativa em Instituições de Ensino Superior: um estudo do modelo ACSI através de Equações Estruturais. In: ENCONTRO NACIONAL DE PROGRAMAS DE PÓS-GRADUAÇÃO EM ADMINISTRAÇÃO, 2003, Atibaia. Anais... Porto Alegre: Pallotti, 2003. 1 CD-ROM.

HAIR JÚNIOR, Joseph F; ANDERSON, Rolph E; TATHAM, Ronald L; BLACK, William C. Análise multivariada de dados. 5. ed. Porto Alegre: Bookman, 2005.

HENNIG-THURAU, Thorsten; LANGER, Markus F.; HANSEN, Ursula. Modeling and managing student loyalty: an approach based on the concept of relationship quality. Journal of Service Research, v. 3, n. 4, p. 331-344, may. 2001.

KAREMERA, David; REUBEN, Lucy J.; SILLAH, Marion R. The effects of academic environment and background characteristics on student satisfaction and performance: the case of south Carolina state University's school of business. College Student Journal, v. 37, n. 2, p. 298-308, 2003.

KAWAKITA, J.; The Original KJ Method. Tokyo: Kawakita Research Institute, 1991.

KATO, Naotaka; KUNIFUJI, Susumu. Consensus-making support system for creative problem solving. Knowledge-Based Systems, v.10, p.59-66, 1997.

LAKATOS E. M.; MARCONI, M. A. Fundamentos de metodologia científica. 3. ed. São Paulo: Atlas, 1996.

LEE, Mark C.; NEWCOMB, John. Aplication of the Language Processing (LP) Method to Shorten the NASA Flight Experiment Development Cycle. Center for Quality of Management Journal, v.5, n.2, p. 15-26, fall, 1996. 
LIMA, Edmilson de Oliveira. Métodos Qualitativos em Administração: teorizando a partir de Dados sobre Processos em uma Recente Pesquisa. In: ENCONTRO NACIONAL DE PROGRAMAS DE PÓS-GRADUAÇÃO EM ADMINISTRAÇÃO, 2005, Brasília. Anais..., Porto Alegre: Pallotti, 2005. 1 CD-ROM.

MARKS, Ronald B. Determinants of student evaluations of global measures of instructor and course value. Journal of Marketing Education, v. 22, n. 2, p. 108-119, aug. 2000. Disponível em: <http://jmd.sagepub.com/cgi/reprint/22/2/108.pdf>. Acesso em: $10 \mathrm{dez}$. 2005.

MARZO-NAVARRO, Mercedes; PEDRAJA-IGLESIAS, Marta; RIVERA-TORRES, M. Pilar. Measuring customer satisfaction in summer courses. Journal Quality Assurance in Education, v. 13, n. 1, p. 56-65, 2005. Disponível em: <http://www.emeralinsight.com/ 0968-4883.htm>. Acesso em: $10 \mathrm{dez} .2005$.

MATTAR, Fauze N. Pesquisa de Marketing. São Paulo: Atlas, 1996.

MIZUNO, Shigeru. Gerência para melhoria da qualidade: as sete novas ferramentas de controle da qualidade. Rio de Janeiro: Livros Técnicos e Científicos, 1993.

REA, Louis M.; PARKER, Richard A. Metodologia de pesquisa: do planejamento à execução. São Paulo: Pioneira, 2000.

RUEDIGER, Marco Aurélio; RICCIO, Vicente. In: VIEIRA, Marcelo Milano Falcão; ZOUAIN, Deborah Moraes.(Org.). Pesquisa qualitativa em administração. Rio de Janeiro: FGV, 2004. p. $151-172$.

SHIBA, Shoji. The Language Processing Method. Document ML0060. Boston: The Center for Quality Management, 1994.

WALTER, Silvana Anita; DREHER, Marialva Tomio. Qualidade e ética nos instrumentos de avaliação de satisfação de alunos nos cursos de administração do Sistema ACAFE: ação de empreendedorismo social. In: ENCONTRO ANUAL DA ASSOCIAÇÃO NACIONAL DOS CURSOS DE GRADUAÇÃO EM ADMINISTRAÇÃO, 16, 2005, Belo Horizonte. Anais... Rio de Janeiro: ANGRAD, 2005. p. 248-262. 1 CD-ROM.

WALTER, Silvana Anita; TONTINI, Gérson; DOMINGUES, Maria José Carvalho de Souza. Identificando oportunidades de melhoria em um curso superior através da análise da satisfação dos alunos. In: ENCONTRO NACIONAL DE PROGRAMAS DE PÓSGRADUAÇÃO EM ADMINISTRAÇÃO, 2005, Brasília. Anais... Porto Alegre: Pallotti, 2005. 1 CD-ROM.

WILHELM, Wendy B. (2004). The relative influence of published teaching evaluations and other instructor attributes on course choice. Journal of Marketing Education, v. 26, n. 1, p. 17-30, abr. 2004. 


\title{
IDENTIFICATION OF IMPROVEMENT OPPORTUNITIES IN A MANAGEMENT COURSE BY MEANS OF QUALITATIVE METHODS OF INFORMATION PROCESSING
}

\begin{abstract}
This article has as its aim to present a methodological approach of a recent survey which uses qualitative methods of focus groups and affinity diagrams to identify improvement opportunities in undergraduate business management courses. In the cited survey, six focus groups of a Higher Education Institution (HEI) located in Curitiba, PR were interviewed. Through a hierarchic processing method of the problems mentioned by the different groups, the study allowed to transform a diffuse and unstructured knowledge into structured knowledge, identifying and ranking the 15 main problems of the $\mathrm{HEl}$ surveyed Management Course. This work demonstrates that the focus groups are an alternative for the identification of improvement opportunities without previously distinguishing the problems. As main conclusions we have that the course must promote the content integration of disciplines and improve the teacher-student relationship, trying to settle a partnership relationship in the teaching-learning process. Concerning to the infrastructure, the HEI must initially solve access aspects (waiting time, access, etc.). The used methodological procedures can inspire other initiatives in the Brazilian HEls context.
\end{abstract}

Key words: Qualitative Survey. Focus Group. Academic Management. 